\title{
Youth tobacco prevention mass media campaigns: past, present, and future directions
}

\author{
M C Farrelly, J Niederdeppe, J Yarsevich
}

Tobacco Control 2003;12(Suppl I):i35-i47

This paper focuses on countermarketing efforts aimed at curbing youth smoking. We review the literature on the effectiveness of tobacco countermarketing campaigns, characterise current state and national campaign approaches, present findings from qualitative approaches and laboratory experiments that explore a variety of messages (for example, health consequences, industry manipulation), and discuss newer, non-traditional approaches to countermarketing. In conclusion, we outline research needed to fill gaps in our existing knowledge and discuss future directions in tobacco countermarketing aimed at youth.

See end of article for authors' affiliations

Correspondence to: Matthew C Farrelly, PhD, Tobacco Use Research Program, Health, Social and Economics Research, Research Triangle Institute, PO Box 12194, Research Triangle Park, NC 27709,

USA; mcf@rti.org
$\mathrm{T}$ he landscape in tobacco control has changed dramatically in the past two decades. An influx of significant funds for tobacco control began in the mid 1980s with dedicated state excise taxes, federal support for tobacco control began in the early 1990s, and settlements with the tobacco industry provided additional support more recently. Settlements between the tobacco Minnesota, Mississippi, and Texas) and with 46 states in the 1998 Master Settlement Agreement (MSA) have added to an historic tobacco control opportunity with over $\$ 200$ billion in funds to states over 25 years. In addition, the MSA set aside $\$ 2$ billion to create the American Legacy Foundation (Legacy), dedicated exclusively to national tobacco control efforts. Although some have criticised the lack of commitment of settlement funds by state legislatures to tobacco control, ${ }^{1}$ fig 1 illustrates a dramatic rise in funding available to states from the 1980 s to $2000 .^{2}$ These funds include resources from state cigarette excise taxes, general funds, tobacco settlements, and funds from the Centers for Disease Control and Prevention (CDC) and national foundations (for example, Legacy, Robert Wood Johnson Foundation). The new opportunities these funds represent give rise to important questions for state programme administrators. This paper attempts to answer questions about different approaches used by mass media campaigns and other forms of tobacco countermarketing and their relative effectiveness at curbing tobacco use among youth and adults.

Current state and national media campaign approaches are diverse; some focus exclusively on a single target audience with a focused message strategy (for example, Florida's "industry manipulation" campaign targeted exclusively to teens), while others use multiple message themes to curb smoking across the entire population. Newer, complementary elements of countermarindustry and individual states (that is, Florida, keting include "branding" anti-tobacco campaigns, carefully targeting campaign messages to high risk and special audiences, building youth movements against tobacco, distributing antitobacco gear (for example, T shirts, hats, posters, stickers), and other grassroots marketing techniques. Anti-tobacco gear serves as tobacco control's answer to the tobacco industry's "trinkets and trash" programmes, such as Camel Cash and Marlboro Miles. Youth groups are designed to disseminate anti-tobacco messages through peer communication, to counter tobacco advertising influences in the community, and to develop future generations of tobacco control activists.

Figure 1 illustrates that nationally in 2000, tobacco control expenditures peaked at just over \$2 per capita. To put countermarketing and tobacco control expenditures in perspective, it is instructive to examine cigarette advertising. Although the tobacco industry cannot advertise on television, radio, or billboards, in 2000 it spent $\$ 694$ million or roughly \$2.50 per US resident on advertising (magazines, newspapers, transit, and point-of-sale ads) and a record high $\$ 9.57$ billion or \$34 per person on all advertising and promotions, including coupons, retail value added, and "promotional allowances". ${ }^{3}$ The MSA imposed substantial restrictions on the advertising outlets available to the tobacco industry, but promotional expenditures have continued to rise: tobacco industry promotional spending has increased by $87 \%$ since 1996 . Restrictions on print, billboard, and "trinkets and trash" advertising have forced the tobacco industry to seek new and innovative ways to reach the public, including event sponsorship and promotions at "adultonly" establishments. ${ }^{45}$ Changing tobacco marketing strategies present substantial challenges for tobacco control advocates and obviate the need for novel countermarketing strategies to keep pace.

In this paper, we focus primarily on countermarketing efforts aimed at curbing youth smoking. We review the literature on the effectiveness of mass media campaigns, characterise current state and national campaign approaches, and discuss campaign message strategies and newer approaches to countermarketing. We conclude by outlining research needed to fill gaps in our existing knowledge.

Abbreviations: CDC, Centers for Disease Control and Prevention; ETS, environmental tobacco smoke; FCC, Federal Communications Commission; FYTS, Florida Youth Tobacco Survey; GRPs, gross rating points; LMTS, Legacy Media Tracking Surveys; MSA, Master Settlement Agreement; MSDH, Mississippi Department of Health; MTF, Monitoring the Future; SWAT, Students Working Against Tobacco; TDS, "Think. Don't Smoke" TPEP, Tobacco Prevention and Education Program 


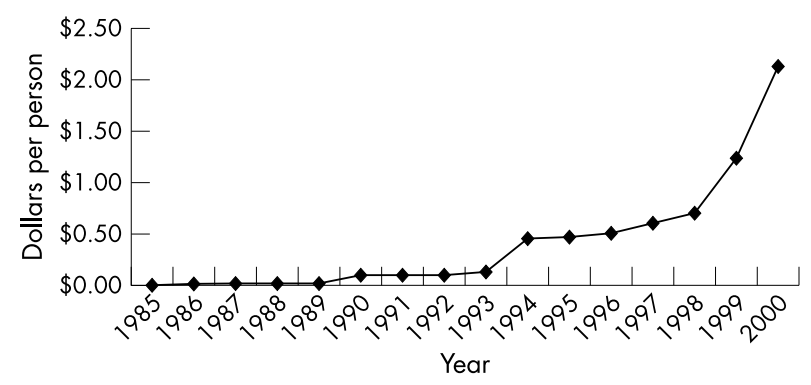

Figure 1 Average state level funding for tobacco control (in real per capita dollars). ${ }^{2}$

\section{EFFECTIVENESS OF ANTI-SMOKING MEDIA CAMPAIGNS}

Evaluations of the potential impact of anti-smoking media campaigns on tobacco in the USA began in the wake of the 1967 Federal Communications Commission's (FCC) decision that ruled that the Fairness Doctrine applied to cigarette commercials and required a "balance" between anti-smoking and cigarette ads. This balance was later interpreted as calling for a ratio of one free anti-smoking message on television or radio for each three cigarette commercials broadcast. ${ }^{67}$ However, initially this ratio was much higher in favour of cigarette commercials (personal communication, John Banzahf, September 2002). Nevertheless, the anti-smoking television and radio messages that aired between July 1967 and December 1970 as part of the FCC's Fairness Doctrine reduced aggregate smoking ${ }^{8}$ and smoking among adolescents, particularly during the first year of the anti-smoking messages. ${ }^{10}$ Schneider $e t$ $a l^{11}$ estimated that the anti-smoking messages reduced per capita consumption by $5 \%$. The messages in this campaign focused on the health consequences of smoking, at times employing fear inducing strategies ${ }^{72}$-at that time, the presence of anti-smoking messages on television was a groundbreaking event.

In the 1980s, smoking prevention campaigns shifted focus away from long term health effects messages to psychosocial approaches, which attempted to influence youth awareness of short term consequences of smoking (for example, bad breath and inability to keep up in sports), raise consciousness of social pressures and influences to smoke (for example, parental and peer smoking), and teach youth skills to resist peer pressure to smoke. ${ }^{13}$ More recently, several campaigns have employed a strategy focused on portraying the manipulative behaviour of the tobacco industry. ${ }^{14}{ }^{15}$ A number of experimental studies and evaluations of state and national campaigns explore the effectiveness of the psychosocial and counterindustry strategies. We examine each of these sets of studies separately.

\section{Experimental studies}

In contrast to the evaluations of the Fairness Doctrine campaign, more recent evaluations paint a more complicated picture of campaign effectiveness. For example, Bauman et $\mathrm{al}^{16}$ found that a mass media campaign affected friends' approval of smoking and adolescents' subjective expected utility of smoking but not smoking behaviour. The messages used in the study's campaign were extensively tested and focused on short term consequences of cigarette smoking. The null effects on smoking in Bauman et al $^{16}$ may have been due to the lack of complementary interventions, insufficient campaign exposure, or an ineffective message strategy. Others have found anti-tobacco advertising campaigns to be effective when accompanied by school or community based programmes. ${ }^{17-21}$

Flynn et $a l^{17}$ found that a four year paid advertising campaign in Montana and New England was effective in reducing youth smoking. Smoking rates were $34 \%$ to $41 \%$ lower among students exposed to both the anti-tobacco advertising campaign and the school programmes in comparison to those exposed to the school programme alone. Flynn et $a l^{21}$ returned to these communities two years after the intervention and found that previous effects persisted. This campaign used the psychosocial approach aimed to correct perceptions of social norms, improve refusal skills, generate more negative views of smoking, and facilitate more positive views of not smoking. ${ }^{17}$

Perry $e t \mathrm{al}^{18}$ conducted a substudy of the Minnesota Heart Health Program focused on smoking prevention and followed sixth graders in 1983 longitudinally to 1989. This study included school based education in the context of a community wide intervention that included a mass media campaign and other interventions to promote heart healthy behaviour among adults. School based interventions were conducted based on the psychosocial approach from 1983 to 1985. The mass media campaign was designed to reinforce these messages. This study found lower smoking rates and intensity in treatment groups relative to control communities that were sustained through the 12th grade. In the 12 th grade, the weekly prevalence of smoking was roughly $40 \%$ lower in the intervention group than in the control community. ${ }^{18}$

In a study conducted in Norway, three distinct media campaigns were directed at adolescents in one county in consecutive springs from 1992 to $1995 .{ }^{22}$ Each campaign was three weeks in duration and included one television commercial, a movie trailer, a newspaper advertisement, and a poster for the local schools and youth organisations. The three campaigns were intended to evoke affective reactions and stimulation communication among peers. Two of the campaigns were directed at girls and one was directed at both girls and boys. The theme of the first campaign was that "girls are stupid because the more we know about the health hazards of smoking, the more Norwegian girls start to smoke". ${ }^{22}$ The second campaign sent the message that smoking indicates a lack of self control and that smoking is at variance with ideals of environmental protection. Finally, the third campaign tied smoking to poor performance at school and work. A baseline survey of all eligible youth aged 14 and 15 years was conducted in the intervention and a control county before the first media campaign in 1992. A similar survey was conducted in 1995 after the final campaign. Survey results show that non-smoking youth at baseline were less likely to smoke at follow up in the intervention county compared with youth in the control county. In addition, adolescent girls who smoked at baseline were less likely to continue to smoke at follow up in the intervention county compared with girls in the control county. The same was not true for boys.

A recent experimental study evaluated the Texas Tobacco Prevention Initiative where 14 East Texas counties were assigned to one of three levels of media (that is, none, low (\$0.50 per capita), or high ( $\$ 1.00$ per capita)) and one of five levels of community programmes. ${ }^{19}$ The prevention messages focused on the theme "tobacco is foul". The \$2 million "Tobacco is foul" campaign consisted of animated cartoon ads featuring a hip-talking duck and hip-hop music. The idea of an animated campaign arose from Texas teenagers themselves during an anti-tobacco workshop. The ads were aired in English and Spanish and were specifically targeted to Hispanic, African American, and Asian American sixth, seventh, and eighth graders. ${ }^{23}$ Each ad portrays the non-smoking duck looking cool, while others who smoke act stressed out or exhibit gross behaviour and are essentially not cool. The community options included: (1) no community programmes; (2) law enforcement programmes only; (3) cessation programmes only; (4) school-community prevention programmes only; or (5) all programmes combined. With five levels of community programmes and three levels of media, this constitutes 15 possible combinations. The combination of no media campaign and multiple community programmes was not included 
as one of the combinations, leaving one combination for each of the 14 counties. The youth media campaign was targeted to 11-12 years olds. The other youth programmes included school based tobacco prevention in middle ("Towards no tobacco") and high ("Teens against tobacco use") schools and greater enforcement of youth access laws. The evaluation focused on sixth graders and compared changes in smoking rates across conditions using a pre/post cross-sectional survey design. Sixth graders were interviewed in the spring before the intervention, and then a new wave of sixth graders was surveyed in November and December of the same year (after the school based programmes were delivered). Prevalence of any tobacco use among youth ranged from $5-28 \%$ in the prewave and $3-24 \%$ in the post-wave. The prevalence of use was lower in all counties because the students were surveyed earlier in the school year. ${ }^{19}$

Preliminary results of the study indicate that the average percentage reductions were:

- $35 \%$ in areas with no media or low level media and no programmes or single cessation or enforcement programmes

- $44 \%$ in areas with no or low media and school-community programmes or multiple programmes

- $24 \%$ in areas with high media and no programmes or a single cessation or enforcement programme

- $60 \%$ in areas with high media and school-community programmes or multiple programmes.

While the largest decline was for the latter group that includes a high dose of media, the overall pattern of results does not provide a clear dose-response relation. However, the authors indicate that there was a statistically significant interaction between programme type and media level. ${ }^{19}$ It is not clear yet how long these effects will persist beyond the study period.

Findings from these controlled experiments indicate that anti-tobacco advertising campaigns have the potential to decrease tobacco use among youth. There is some evidence that media campaigns are more likely to succeed when coordinated with school or community based tobacco prevention, but more research is needed to better understand synergies across interventions.

Next, we explore the effectiveness of state and national mass media campaigns. The primary hurdle in evaluating these campaigns is that, unlike controlled experiments, it is difficult to separate the independent effect of anti-tobacco advertising campaigns on youth tobacco use above and beyond other factors in real world settings.

\section{Statewide mass media campaigns}

Turning to statewide media campaigns, a number of states have mounted large mass media efforts targeted to all ages, and other states have focused on youth prevention. A number of the evaluation studies have shown an impact of these campaigns on per capita cigarette sales, ${ }^{24-26}$ and a few have focused on the impact on youth smoking. Because youth represent a relatively small share of total cigarette sales, impacting overall sales does not necessarily imply a reduction in youth smoking. Given the difficulty in teasing out effects for the media campaign separate from other programme components, we assess the evidence for programme and media campaign effectiveness separately.

In 1986, Minnesota was the first state to implement a statewide anti-smoking campaign. ${ }^{27}$ The campaign spent nearly \$1 million annually from 1986 to 1989 and \$1.6 million in 1990 and 1991, or roughly $\$ 0.35$ per capita. Murray et $a^{27}$ evaluated the effect of Minnesota's 1986 to 1990 anti-tobacco advertising campaign on beliefs and smoking behaviour of youth relative to Wisconsin youth where no comparable programme was in place. The authors found that the advertising campaign increased self reported exposure to anti- smoking messages but that this exposure did not significantly change beliefs or tobacco use behaviour. The authors attribute the results to a lack of widely used concomitant school based tobacco prevention programme. Another possible explanation is the relatively low level of funding to adequately reach the target audience. This is illustrated by the small magnitude of difference in self reported exposure to anti-smoking messages. Campaign messages focused on the social influences that encourage teens to smoke cigarettes. ${ }^{27}$

Recent state media campaigns are often one component of a larger, comprehensive approach to tobacco control that includes tobacco prevention education in schools, community and school based programmes, and tobacco control policy environment changes (for example, excise taxes, clean indoor air laws, youth access restrictions, and enforcement). California was the first to mount a large, multimillion dollar comprehensive programme in 1989. For such programmes, mass media campaigns are just one component, and therefore it is challenging to isolate the impact of the media campaign. A trend analysis by Pierce et $\mathrm{al}^{26}$ shows that smoking prevalence among adults and cigarette sales (primarily driven by adults) declined faster in California than in the rest of the USA. Although the mass media campaign was a significant component of the programme, many other factors could have contributed to this difference, especially the $\$ 0.25$ tax increase that funded the programme. Such trend analyses are also limited by the fact that they cannot control for other nonprogramme related trends that were unique to California and may have influenced smoking.

However, Hu et $\mathrm{al}^{25}$ performed a multivariate analysis and attempted to control for other potential confounding effects. They found that expenditures on anti-smoking messages in California reduced aggregate cigarette sales, controlling for changes in cigarette excise taxes and a proxy of pro-tobacco advertising but not other components of the tobacco control programme (for example, changes in local clean indoor air policies). However, declines in aggregate sales do not help determine whether the campaign decreased tobacco use among youth and/or adults. Once again, to the extent that there were pre-existing trends in California that led to the adoption of the programme and to simultaneous declines in smoking, the results of this analysis may overstate the effects of the media campaign on smoking.

Popham et $a l^{28}$ focused on the mass media campaign and examined the association between recall of California's media campaign and self reported smoking behaviour and attitudes among youth and adults in the first two years of the campaign-a period before the launch of other programme activities. This study found no statistically significant relation between smoking and campaign exposure among either youth or adults. However, the longer term trends in youth smoking from Monitoring the Future (MTF) ${ }^{29}$ (eighth to 12th grade averages) for California and the rest of the USA show that while smoking was on the rise in the 1990s for both California and the USA, rates were rising less rapidly in California. To examine these data using slightly more formal statistics, we estimated a simple linear regression that includes a quadratic time trend covering both the USA and California, a California specific indicator variable and quadratic time trend, and real cigarette excise taxes. This simple model explains $99 \%$ of the variation in 12th grade smoking rates and shows that the average rate of increase over this time period was 3.2\% for the USA but only $1.4 \%$ for California, controlling for the effects of taxes. This suggests that California's tobacco control programme has been successful at curbing youth smoking relative to the country as a whole. In addition, smoking rates were 16.8 percentage points lower in California on average (fig 2).

Massachusetts launched its tobacco control programme in 1994 with a comprehensive tobacco control programme that included an anti-tobacco media campaign targeted primarily 


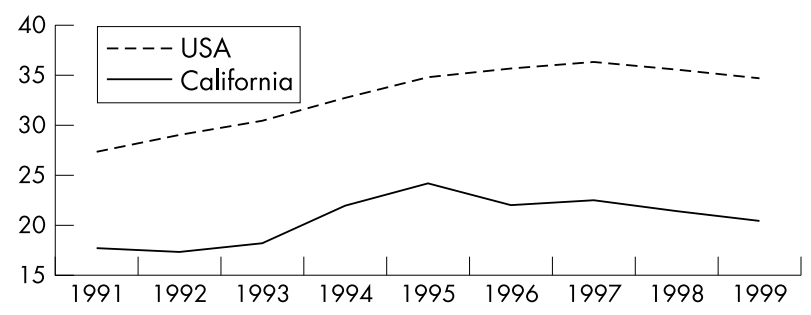

Figure 2 Smoking rates for high school seniors in California and the USA minus California, 1991 to 1999 Monitoring the Future. ${ }^{39}$

to adults but complemented with some youth prevention messages. The Massachusetts programme started at a time when youth smoking rates were on the rise. According to a recent evaluation report, youth smoking rates in Massachusetts mirrored smoking rates nationwide from 1993 to 1995 and then declined faster in Massachusetts than in the rest of the nation from 1997 to $1999 .{ }^{30}$ In a four year follow up survey of Massachusetts youth, Siegel and Biener ${ }^{31}$ show that 12-13 year olds exposed to the Massachusetts campaign were less likely to become smokers than teens who were not exposed. A limitation of this approach is that teens who are more likely to recall the messages may have been disposed to not smoke compared with those who did not recall the messages. In addition, this effect was not present for 14-15 year olds. However, combined, these studies provide fairly convincing evidence that, in the context of a comprehensive tobacco control programme, Massachusetts' media campaign was able to reduce smoking initiation among younger teens.

In January 1996, Arizona launched a youth prevention mass media campaign entitled "tobacco a tumour-causing, teeth-staining, smelly, puking habit". Unfortunately, there were no surveys of youth conducted before or in the first few years of the campaign (MTF data for Arizona are not available), and as a result, it is impossible to understand the impact of the campaign on Arizona youth.

In November 1996, Oregon voters passed Measure 44 that approved an excise tax increase of $\$ 0.30$ and allocated $10 \%$ of the revenue to a statewide Tobacco Prevention and Education Program (TPEP), including a mass media campaign. During the first two years of their mass media campaign, TPEP spent $\$ 4.6$ million or $27 \%$ of its $\$ 17$ million budget. Since the launch of TPEP, per capita cigarette sales (which reflect primarily adult smoking) have declined faster in Oregon than in the total USA. ${ }^{23}$ TPEP's school based tobacco prevention programme has also been shown to be successful, ${ }^{33}$ but no study has focused on the impact of their campaign on youth or adult smoking. Campaign messages have focused on a mixture of youth prevention, environmental tobacco smoke (ETS), and adult cessation.

Starting in 1998 with Florida's "truth" campaign and the 1998 MSA, there has been an explosion of mass media campaigns, including targeted youth prevention campaigns (discussed below in detail). Because most other youth campaigns started very recently, there are not yet evaluation reports or journal articles discussing the effectiveness of many of the campaigns. States with large youth prevention campaigns include Mississippi and Minnesota that began in 1999 and 2000, respectively.

In 1998, Florida launched an aggressive, youth prevention campaign known as "truth" in the context of a multifaceted tobacco prevention programme that included school and community tobacco prevention efforts. The goal of "truth" was to counter tobacco influences with hard hitting ads that feature youths confronting the tobacco industry. Results from the Florida Youth Tobacco Survey (FYTS) showed a drop in smoking among middle and high school students of $18 \%$ and
$8 \%$, respectively, after year one (spring 1998 to spring 1999) and $40 \%$ and $18 \%$ after year two (spring 1998 to spring 2000). ${ }^{34}$ From spring 1998 to spring 2000, smoking rates declined by $14.5 \%$ among eighth, 10th, and 12th graders on average and $11.8 \%$ among 10th and 12th graders from the MTF surveys conducted each spring. It appears that smoking rates were declining faster in Florida than the rest of the country among high school age students. There is no national comparison for the sixth grade to eighth grade FYTS sample.

In addition, Sly et $a l^{35}$ conducted a longitudinal survey and found that non-smoking teens (in time 1 of the survey) exposed to the "truth" campaign (reported retrospectively in the time 2 survey) were less likely to smoke in a follow up survey, 5-10 months after the initial survey. This study was conducted during the first year of the campaign. To measure exposure to the campaign, Sly et al developed an "advertising effectiveness index" that ranged from $0-2$. The measure is equal to 0 if a teen did not report awareness of any "truth" ads in the time 2 survey. It is equal to 2 if they reported awareness of two "truth" ads, found that the ads "made them think about whether or not they should smoke", and were influenced by feeling that tobacco companies were just trying to use them. The index is equal to 1 for all other non-smoking respondents from time 1 who reported awareness of "truth" in time 2. Although there is some evidence that the appeal of messages ${ }^{35}{ }^{36}$ has an impact on behaviour above and beyond exposure, the inclusion of an attitude about the tobacco industry into the index-feeling that tobacco companies were just trying to use them-is troubling because it is an intermediate outcome of the campaign. Therefore, those who were always predisposed against tobacco companies and presumably less likely to smoke were given a higher score on the index. As a result, the campaign effect size may be overstated. In addition, Sly et al $^{15}$ did not control for the potential effects of other programme components, including tobacco use prevention education in schools and community organisations and activities, arguing that there was little exposure to these other programme components during the first year of the programme.

Some assert that a portion of the decline in Florida can be attributed to the November $1998 \$ 0.45$ per pack price increase. Farrelly et $a^{14}$ noted that cigarette prices increased by roughly $30 \%$ during the first year of the Florida "truth" campaign and by $7 \%$ during the second year. For these price increases, economic studies project a $10-20 \%$ decline in youth smoking prevalence for 1998 and a $2-5 \%$ decline for 1999 . This suggests that a significant fraction of the drop in smoking after the first year of Florida's programme may be due to price increases but that the price increase alone cannot account for the entire decline in 1998 or for the continued decline in smoking in 1999.

In 1997, \$62 million was placed in escrow for Mississippi to develop a pilot programme to reduce tobacco use among youth. In March 1999, Mississippi launched its campaign, "Question it", that initially focused on the tobacco industry and then branched out to include messages about the short and long term consequences of smoking, emphasising humorous ads. To date, there are mixed results for the programme. Based on the Youth Tobacco Surveys from 1998 to $2000,{ }^{37}{ }^{38}$ there have not been statistically significant declines in middle or high school smoking rates. The prevalence of smoking among middle school students was 20.6\% (95\% confidence interval of \pm 2.7 percentage points) in spring 1998 and $18.1 \%$ ( \pm 2.3 percentage points) in spring 2000 . Among public high school students, the comparable rates are $30.3 \%( \pm 3.8 \%)$ and $29.2 \%( \pm 3.6 \%)$, respectively. However, based on the Youth Risk Behaviour Surveys from 1999 to 2001, the Mississippi Department of Health (MSDH) has reported statistically significant declines in smoking among both public middle and high school students. The prevalence of smoking among high school students declined 25\% from 31.5\% to 23.6\% (1999 and 
2001 YRBS Reports, MSDH).* This compares favourably to the $19 \%$ decline during the same time period among eighth to 12 th graders from MTF. The MSDH also issued a press release in 2001 indicating that current smoking rates declined 30.4\% among public middle school students from 1999 to 2001.† Results from these two surveys imply that smoking rates declined only after 2000. There are currently no evaluations of the state's media campaign.

Minnesota's Target Market campaign began in April 2000 and within a year of the programme launch, the prevalence of smoking in the past 21 days among 12-17 year olds declined from $13 \%$ to $8 \%$ (38\% decline), and any tobacco use declined from $16 \%$ to $12 \%$ (25\% decline). According to $\mathrm{MTF}^{29}$ smoking during the past month among eighth to 12th graders declined by $9.9 \%$, which is a significantly slower pace than the declines in Minnesota.ł During this time, Minnesota did not have any cigarette excise tax increases.

In summary, there is growing evidence that aggressive youth prevention campaigns in states have been effective at reducing youth tobacco use, but it is still unclear to what extent increases in cigarette prices and other concurrent programmes contributed to these declines.

\section{National anti-tobacco campaigns}

In recent years, three national youth prevention campaigns have been implemented. In December 1998, Philip Morris launched its Youth Smoking Prevention programme, which included a national media campaign known as "Think. Don't Smoke" (TDS). The annual budget for the entire Philip Morris programme was over $\$ 100$ million ( $0.4 \%$ of 2001 revenue) before the programme was withdrawn in spring 2002. In November 1999, Lorillard began its smoking prevention media campaign, "Tobacco is Whacko, if You're a Teen". This campaign is considerably smaller than the Philip Morris campaign with an annual budget of $\$ 12-13$ million (0.3\% of 2001 revenue) (Jordan Bressler, Lorillard, personal communication, 2002). In early February 2000, Legacy launched truth ${ }^{\mathrm{sm}}$, a national tobacco countermarketing campaign, by an alliance of advertising firms led by Arnold Communications, Legacy staff, and nationwide youth. truth ${ }^{\mathrm{sm}}$ targets primarily $12-17$ year olds who are susceptible to smoking and was inspired by the Florida "truth" campaign. Legacy spends $\$ 100$ million annually on truth ${ }^{\mathrm{sm}}$.

The CDC's Office on Smoking and Health has also produced a series of ads for use in statewide and national tobacco countermarketing campaigns. These messages feature celebrity spokespeople, including Christy Turlington and Jeremy London, who discuss the consequences of losing a loved one to smoking related diseases and highlight the negative effects of cigarette smoke. Another ad features the musical group Boyz II Men discussing how cigarette smoke negatively affects their ability to sing in tune.

Evaluating the impact of national campaigns on smoking is challenging because there are no readily available comparison groups. All three of these campaigns are occurring at a time when tobacco use has been declining nationally (after a period of sharp increase). In addition, the MSA and lawsuits about tobacco have also generated press coverage of the tobacco issue. To evaluate the potential impact of these campaigns, it is necessary to show that:

- the target population was exposed to a meaningful dose of messages

\footnotetext{
*Confidence intervals are not clearly reported in these summaries. †Specific prevalence rates and confidence intervals were not reported. $\ddagger$ The unusual reporting period for smoking in the past three weeks in the Minnesota study makes comparisons to national trends somewhat less relevant. However, to the extent that the prevalence of smoking in the past 21 days is a reasonable proxy for smoking in the past 30 days, this comparison will still be valid.
}

- youth who saw campaign ads evaluated them positively

- youth with higher levels of exposure to ads had more antitobacco beliefs, intentions, and/or behaviour, controlling for the influence of other factors

- those who were exposed to ads were less likely to smoke.

Unfortunately, each campaign has not been sufficiently studied to assess each of these points. We discuss the available data below.

Philip Morris's approach has been criticised as unappealing to youth, ${ }^{14}{ }^{40}$ ineffective, ${ }^{14}$ and more about buying credibility than about reducing youth smoking. ${ }^{41}$ Farrelly et $a l^{14}$ find that exposure to TDS is associated with more positive attitudes toward the industry and increased intentions toward future smoking but more negative attitudes about the social desirability of smoking. It should be noted that self reported reactions to the TDS ads among a nationally representative sample of 12-17 years old were generally positive among youth overall, but receptivity to these messages was negatively correlated with intentions to smoke and smoking behaviour. ${ }^{40}$ In contrast, reactions to the truth ${ }^{\mathrm{sm}}$ campaign among 12-17 year olds were equally positive regardless of youth's smoking status. $^{40}$ Roughly two thirds and $75 \%$ of $12-17$ year olds reported awareness of the TDS and truth ${ }^{\mathrm{sm}}$ campaigns, respectively, in fall 2000. ${ }^{140}$ There have not been any published evaluations of Lorillard's “Tobacco Is Whacko, If You're a Teen" campaign.

The results of Farrelly et al ${ }^{1439} 40$ are based on the Legacy Media Tracking Surveys (LMTS), which are designed to produce nationally representative samples of youth aged 12-17 years. The surveys measure exposure to ETS, access to tobacco products, knowledge and attitudes about tobacco, awareness of pro- and counter-tobacco advertising, and self reported tobacco use and intentions. Before the truth ${ }^{\mathrm{sm}}$ campaign (launched on 7 February 2000), the baseline telephone survey (LMTS-I) was conducted between 6 December 1999 and 6 February 2000. The next telephone survey (LMTS-II) was conducted between 8 September 2000 and 23 December 2000.

The LMTS contained questions to measure awareness television ads from truth ${ }^{\mathrm{sm}}$ and TDS. Respondents were asked about their awareness of specific campaign ads by asking youth whether they have "recently seen an anti-smoking or anti-tobacco ad on TV that showed ..." followed by a brief description of the beginning of the ad. The ad descriptions were intended to provide enough information to recognise the ad in question but not enough information for the respondent to "fake" awareness of the ad..$^{35}$ Once a respondent indicated recognition, they were then asked to report further ad details to awareness. Confirmed awareness of at least one ad indicated campaign awareness or exposure. Questions pertaining to the various ads were presented in random order to control for order effects and included all ads from both campaigns aired within six weeks of the survey start. ${ }^{14}$

Farrelly et $a l^{14}$ found that the percentage of 12-17 year olds who agreed with several attitudes that are central to the truth $^{\mathrm{sm}}$ campaign increased by a range of $7-26 \%$ in the first 10 months of the truth ${ }^{\mathrm{sm}}$ campaign. The authors estimated multivariate models for each of the attitudes as a function of exposure to the truth ${ }^{\mathrm{sm}}$ and TDS campaign as well as other factors (for example, age, race/ethnicity, sex, income) and found that exposure to the truth ${ }^{\mathrm{sm}}$ campaign was associated with changes in attitudes and intentions to smoke. A limitation of this study is that it relies on cross sectional surveys. Farrelly and colleagues note that those who recall tobacco countermarketing messages may be different from those who do not. As a result, some of the association between changes in attitudes and exposure to the rruth $^{\mathrm{sm}}$ campaign may reflect the fact that those who have stronger anti-tobacco attitudes may be more attentive to the campaign. Similarly, those with favourable attitudes toward the tobacco industry may be more attentive to Philip Morris's efforts to curb youth smoking. 
More recently, Farrelly et $a l^{42}$ analysed a subset of 69 schools from the National Youth Tobacco Survey that were surveyed in 2000 and again in 2002 to examine the impact of the truth ${ }^{\mathrm{sm}}$ campaign on youth smoking. Based on the campaign's national media buy, media markets throughout the country received a wide range of exposure to truth ${ }^{\mathrm{sm}}$ commercials between 2000 and 2002 as measured by gross rating points (GRPs). Schools were then assigned to low, medium, and high exposure based on cumulative GRPs for their media market over the two year period. Farrelly et $a^{42}$ then examined changes in the percentage of youth who smoked at both waves of the survey and found that smoking rates declined by $11 \%(2.2$ percentage points) in low exposure markets, $21 \% \quad(2.7$ percentage points) in medium exposure markets, and $27 \%$ (5.5 percentage points) in the highest exposure markets. Although this preliminary analysis does not control for the potential confounding influences of state excise taxes and tobacco control policies and programmes, it does suggest that the truth $^{\text {sm }}$ campaign had a strong influence on changes in youth smoking.

\section{Health communication campaigns targeting other behaviours}

There is considerable evidence from public health communication campaigns targeting behaviours other than smoking that the mass media can be used to effectively change health behaviour among targeted populations. Hornik's ${ }^{43}$ recent volume brings together a series of public health campaign evaluations, most of which include mass media messages as a central component, and concludes that these efforts can change behaviour in a meaningful way if "they achieve high levels of exposure and activate a complex process of change in social norms" (page 1). For example, the National High Blood Pressure Education Program was associated with large increases in control of hypertension among adults. ${ }^{44} \mathrm{~A}$ campaign aimed at increasing seat belt use in North Carolina was successful in raising the use of seat belts and reducing highway related injury and death. ${ }^{45}$ The SunSmart campaign in Australia was associated with a significant reduction in exposure to the risk of skin cancer among Melbourne residents. ${ }^{46}$ These campaigns featured significant education efforts through the mass media but also included community efforts, institutional change, and/or increased enforcement to educate and change norms among the adult population.

Turning to teens, recent findings indicate that a well funded, carefully designed, and specifically targeted media campaign alone may be sufficient to change substance abuse behaviour among teens. Palmgreen $e t a^{47}$ designed messages using research and theory based approaches to specifically appeal to teens at high risk for marijuana initiation. Campaign messages aired for four months in two Kentucky counties in 1997 and 1998 and achieved substantial levels of exposure; according to audience ratings data, over $70 \%$ of teens were exposed to a minimum of three campaign ads per week. Results indicate that the campaign was successful in reducing current marijuana use among teens, particularly among those at high risk for marijuana initiation. ${ }^{47}$ These findings highlight the potential impact of mass media campaigns that use research and theory based formative design principles, target at-risk audiences, and generate substantial levels of exposure.

\section{Summary of literature on the effectiveness of mass media campaigns}

Careful examination of the accumulated evidence provides some insight into the characteristics of effective campaigns. Foremost, it is clear that substantial levels of campaign exposure are required before anti-tobacco efforts are likely to have an effect. Several studies also suggest that anti-tobacco media campaigns are most likely to be effective when complemented by school or community based interventions. However, the national truth ${ }^{\mathrm{sm}}$ campaign and campaigns in Florida, Kentucky, and Norway imply that well funded, carefully planned, and specifically targeted media campaigns in isolation can affect teen smoking behaviour. Evidence from evaluations of experimental, state, and national anti-tobacco media campaigns does not illuminate a central message strategy that is associated with consistent behaviour change. In subsequent sections, we characterise the various anti-tobacco messages that have been recently used in state and national campaigns and discuss the literature on the relative effectiveness of these various strategies.

\section{CHARACTERISING STATE AND NATIONAL ANTI-TOBACCO CAMPAIGNS}

As discussed above, unprecedented levels of funding have been made available to states and national foundations in recent years. In accordance with CDC recommendations, many states have chosen to implement countermarketing campaigns as a component of comprehensive tobacco control programmes ${ }^{48}$ We sought to explore the breadth of approaches employed within statewide and national campaigns. According to Siegel, ${ }^{49}$ the thematic message and emotional tone both need to be considered when evaluating the impact of countermarketing campaign messages. We reviewed available ads from existing state and national anti-smoking campaigns that have aired since January 2001 and categorised these (often multidimensional) approaches by theme and emotional tone, loosely based on coding schemes employed in previous studies. ${ }^{50} 51$

Pechmann et al $l^{50}$ categorised campaign strategies into the following groups: disease and death, cosmetics, endangers family, smokers' negative life circumstances, refusal skills, marketing tactics, and industry manipulation. Goldman and Glantz $^{51}$ applied the following classes: industry manipulation, ETS, addiction, cessation, youth access, short term effects, long term effects, and romantic rejection. Based on a thorough examination of available ads, we concluded that previously used categorisation schemes did not cover the breadth of content found in newer campaigns. Since most state campaigns and even individual ads have used multiple themes, a mutually exclusive typology was not viewed as a suitable strategy for classifying campaigns. For example, ads from the national truth ${ }^{\text {sm }}$ campaign present the daily death toll caused by cigarettes (long term consequences) and highlight the tobacco industry's role in glamorising smoking (tobacco industry). As a result, we built on the previously employed categories and added several new domains for our exploratory analysis. Table 1 describes each of the thematic categories. Using these categories, the second and third authors of this report viewed all available ads and came to consensus regarding the description of the thematic content and emotional tone of each ad within a campaign. We identified recurrent themes (those contained in at least $15 \%$ of the available ads) across advertisements within a campaign. Table 2 illustrates the breadth of countermarketing campaign approaches adopted by national and state campaigns with several overlapping thematic dimensions.

Three national campaigns directly target teens and are each fairly distinct from one another. TDS ads implement four distinct approaches to reaching youth with a preventative message. We have categorised these approaches as short term consequences, family consequences, deglamorisation, and social norms. Some individual ads contain more than a single approach. An example of a TDS ad using the short term consequences of smoking is "Karate Girl". The ad shows a male teen smoker struggling in a karate class because he is out of breath and not able to concentrate. His non-smoking friend, on the other hand, excels. Ads that focus on family consequences of smoking, such as "Follow the Leader/ Skateboarder" and "Brothers", demonstrate that teens who do 
Table 1 Media campaign message themes

\begin{tabular}{|c|c|}
\hline Message category & Description \\
\hline \multicolumn{2}{|l|}{ - Consequences } \\
\hline Short term & Short term smoking effects, such as loss of breath, yellow teeth, bad breath, or financial consequences \\
\hline Long term & Long term smoking effects, including disease (emphysema, cancer) and death \\
\hline Family & Familial consequences of smoking and parent or sibling influence on smoking among youth \\
\hline Addiction & Highlights the fact that cigarettes are highly addictive, or portrays individuals with a loss of control over their lives \\
\hline \multicolumn{2}{|l|}{ - Social norms and imagery } \\
\hline Deglamorisation & Explicitly portrays smoking as gross, stupid, crazy, not "cool", silly looking, or unattractive \\
\hline Smoking norms & Dispels perception among teens that everyone smokes; portrays cigarette smoking as an individual choice \\
\hline \multicolumn{2}{|l|}{ - Role models } \\
\hline Smoker as negative role model & Former and current smokers tell their story of how tobacco caused severe consequences for them \\
\hline Celebrity appeals & Uses famous actors, models, or athletes \\
\hline \multicolumn{2}{|l|}{ - Industry and product focus } \\
\hline Tobacco industry & Documents efforts by the industry to deny addictive nature of product, lie, and target teens via advertising \\
\hline Cigarette chemicals & Illustrates that cigarettes contain numerous dangerous chemicals (that is, ammonia) \\
\hline - Secondhand smoke & Highlights the dangers of secondhand smoke, including short (bothers others) and long term (disease) impacts \\
\hline - Youth access & Shows efforts to reduce the sale of cigarettes to minors or demonstrates the legal risks of selling to minors \\
\hline
\end{tabular}

not smoke set a good example for younger children (such as a younger brother). The ad "Fish" deglamorises youth smoking and demonstrates short term consequences of smoking by making a girl smoking at a party look foolish. A male teen approaches her while she is lighting up a cigarette. As she takes her first puff, her face turns into a fish, mocking the shape a person's lips form while smoking. The boy subsequently loses his interest in her. Finally, some TDS ads concentrate mainly on the social norms surrounding the act of youth smoking. These ads show various teens participating in typical teen activities and stating that not smoking was an individual choice they made. This tactic reveals that teens do not need to smoke to have fun and participate in youthful activities. In general, TDS ads feature young, casually dressed teens participating in popular, mainstream activities.

"Tobacco is Whacko, if You're a Teen" features advertisements that deglamorise youth smoking by undermining the perception that smoking is cool and an expression of independence. The ads show youth engaging in cutting edge, risky activities, such as body piercing or sneaking out of their parents' house to go to a party. The youth in these ads reject smoking, evidently willing to take risks but not stupid enough to do something as risky as smoking. In addition, the ads subtly portray short term consequence messages. For instance, in "Piercing Parlor", an old man with yellow, decaying teeth offers a cigarette to a rebellious teen. Naturally, the teen refuses the cigarette offer and responds, "What, do you think I'm crazy?".

A goal of Legacy's truth ${ }^{\mathrm{sm}}$ campaign is to market its message as a brand, like other youth brands (for example, Nike, Sprite), to appeal to youth most at risk of smoking (those who demonstrate an openness to smoking experimentation). truth $^{\mathrm{sm}}$ television and print commercials feature what advertising experts call "edgy" youth who are on the cutting edge of trends, promotional items (for example, $\mathrm{T}$ shirts, stickers), street marketing, and a website (www.thetruth.com). The truth ${ }^{\text {sm }}$ campaign's messages place the emphasis on tobacco industry marketing practices, the dangerous chemicals in cigarettes, and stark facts about death and disease caused by tobacco. For example, one ad entitled "Body Bags" shows teens unloading countless body bags onto a curb outside a high rise building in a major metropolitan area. Multiethnic teens, speaking into bullhorns, articulate to tobacco industry executives on the floors above that smoking kills 1200 people every day.
Turning to state campaigns, of the 37 states that have an active mass media campaign, 24 explicitly target youth with specific advertisements while another eight attempt to reach teens through general audience messages. With respect to message themes (table 2), 30 of the 37 states include ads that address health consequences of smoking-message themes that have been in use since the Fairness Doctrine antismoking ads. ${ }^{20}$ Fourteen campaigns address psychosocial influences, an approach that came into favour in the 1980s in tobacco control ${ }^{13}$ and were applied in Minnesota in the late 1980s, California in the early 1990s, and in several experimental studies. ${ }^{175253} \mathrm{~A}$ more recent phenomenon in campaign messages pertains to tobacco industry behaviour and/or the hazardous nature of tobacco products. This relatively new strategy was first employed in California in the early 1990s, adopted in Massachusetts in the mid 1990s, has been recently used in 20 states, and is the core strategy of Legacy's national youth prevention campaign. In addition, 15 of the 24 states that have a youth prevention component employ the counterindustry approach. Because this approach is gaining in popularity and represents a significant departure from earlier strategies, we describe this approach in greater detail below.

In addition to these various thematic approaches, ads from state and national campaigns often seek to elicit emotional responses from the audience. Based on the conceptual framework outlined by Nabi ${ }^{54}$ we categorised the emotional tone of messages (using the same procedure outlined above) into seven categories: neutral, fear, disgust, sadness, anger, humour, and happiness/pride (table 2). Again, these categories are not mutually exclusive as many campaigns used multiple strategies to elicit different emotions among the target audience. Of the 37 state media campaigns described in table 2, 22 use sadness and 11 employ humour. While only eight employ an angry emotional tone, all eight are youth prevention campaigns.

Research suggests that tobacco countermarketing messages that elicit strong emotional responses can generate greater appeal and effect among young audiences. For example, Biener $^{55}$ concluded that ads with strong, negative emotional content were perceived to be more effective than other strategies among teens. Montazeri and McEwen ${ }^{56}$ found that a "fear inducing" ad was perceived to be more effective than a message featuring a "positive approach". Miller et al ${ }^{57}$ found that ads rated highest on a scale of disgust were the most strongly related to disapproval of smoking and intentions not to smoke. In addition, a series of studies on antidrug messages 


\begin{tabular}{|c|c|c|c|c|c|c|c|c|c|c|c|c|c|c|c|c|c|c|c|c|c|c|c|}
\hline \multicolumn{3}{|c|}{ Campaign information } & \multicolumn{3}{|l|}{ Target } & \multicolumn{11}{|c|}{ Themes } & \multicolumn{7}{|c|}{ Emotional tone } \\
\hline & $\begin{array}{l}\text { Overall } \\
\text { tobacco control } \\
\text { funding } 2002 \\
\text { (per capita) }\end{array}$ & $\begin{array}{l}\text { Media } \\
\text { funding } \\
\text { FY } 2002\end{array}$ & Teens & Adult & $\begin{array}{l}\text { General } \\
\text { audience }\end{array}$ & $\begin{array}{l}\text { Short } \\
\text { term }\end{array}$ & $\begin{array}{l}\text { Long } \\
\text { term }\end{array}$ & Family & Addiction & $\begin{array}{l}\text { Degla- } \\
\text { mor- } \\
\text { isation }\end{array}$ & $\begin{array}{l}\text { Smoking } \\
\text { norms }\end{array}$ & $\begin{array}{l}\text { Negative } \\
\text { role } \\
\text { model }\end{array}$ & $\begin{array}{l}\text { Celebrity } \\
\text { appeals }\end{array}$ & $\begin{array}{l}\text { Y Tobacco } \\
\text { Industry }\end{array}$ & $\begin{array}{l}\text { Cigarette } \\
\text { chemicals }\end{array}$ & $\begin{array}{l}\text { Secondhand } \\
\text { smoke }\end{array}$ & Neutral & Fear & Disgust & † Sadness & Anger & Humour & $\begin{array}{l}\text { Happiness/ } \\
\text { pride }\end{array}$ \\
\hline National truth ${ }^{\mathrm{m}}$ & $\$ 0.35$ & $\$ 100 M$ & $x$ & & & & $x$ & & $x$ & & & & & $x$ & $x$ & & $x$ & & & & & $x$ & \\
\hline Think, Don'† Smoke & $\$ 0.26$ & $\$ 75 \mathrm{M}$ & $x$ & & & $x$ & & $x$ & & $\mathrm{x}$ & $x$ & & & & & & $x$ & & & & & $x$ & $x$ \\
\hline $\begin{array}{l}\text { Tobacco is } \\
\text { Whacko }\end{array}$ & $\$ 0.04$ & $\$ 12.5 \mathrm{M}$ & $\hat{x}$ & & & $x$ & & & & $x$ & & & & & & & $\hat{x}$ & & $x$ & & & & \\
\hline Talk, They'll Listen & $\$ 0.09$ & $\$ 25 M$ & & $x$ & & & & $x$ & & & & & & & & & $x$ & & & & & & \\
\hline Alabama & $\$ 0.14$ & & $x$ & $x$ & & & & $x$ & & & $x$ & & $x$ & & $x$ & $x$ & $x$ & & & $x$ & & & \\
\hline Alaska & $\$ 5.08$ & & $\hat{x}$ & $\hat{x}$ & & & $\mathrm{x}$ & $\hat{x}$ & $x$ & & & $x$ & & $x$ & & $\hat{x}$ & $\hat{x}$ & $x$ & & $\hat{x}$ & $x$ & & \\
\hline Arizona & $\$ 8.04$ & $\$ 12 M$ & & $x$ & & $x$ & $x$ & $x$ & $x$ & & & & & & & $x$ & $x$ & $x$ & & & & $x$ & $x$ \\
\hline California & $\$ 4.17$ & $\$ 45 \mathrm{M}$ & & $x$ & $x$ & & $\mathrm{x}$ & & $x$ & & & $x$ & & $x$ & & & $\mathrm{x}$ & & & $x$ & & & \\
\hline Colorado & $\$ 3.27$ & & $x$ & $\hat{x}$ & $x$ & & $\hat{x}$ & $x$ & $x$ & & & $x$ & $x$ & & $\mathrm{x}$ & $x$ & $\hat{x}$ & & $x$ & $\hat{x}$ & & $x$ & \\
\hline Connecticut & $\$ 0.18$ & & & $x$ & & & $x$ & $x$ & & & & & & & $x$ & $x$ & $x$ & & $x$ & & & & \\
\hline Delaware & $\$ 7.47$ & & & $\hat{x}$ & $x$ & & $\hat{x}$ & $\hat{x}$ & $x$ & & & & & $x$ & & $\hat{x}$ & $\hat{x}$ & $x$ & & & & & \\
\hline Florida & $\$ 2.03$ & $\$ 13 M$ & $x$ & & & & $x$ & & $x$ & & & & & $x$ & $x$ & $x$ & $x$ & & $x$ & & & $x$ & $x$ \\
\hline Georgia & $\$ 2.77$ & & & $x$ & & & & $x$ & & & & & & & & $\hat{x}$ & $\hat{x}$ & $x$ & & $x$ & & & \\
\hline Hawaii & $\$ 3.52$ & & $x$ & $x$ & $x$ & $x$ & & $x$ & & & $x$ & & & & $x$ & $\hat{x}$ & $\hat{x}$ & $x$ & & $\hat{x}$ & & $x$ & \\
\hline Idaho & $\$ 0.91$ & $\$ 500 \mathrm{~K}$ & $x$ & & $x$ & & $x$ & $x$ & $x$ & $x$ & & $x$ & $x$ & $x$ & $x$ & $x$ & $x$ & $x$ & & $x$ & & $x$ & \\
\hline Illinois & $\$ 3.86$ & & $\hat{x}$ & & & $x$ & $\hat{x}$ & & & $\hat{x}$ & $x$ & & & & & $\hat{x}$ & & & & & & $\hat{x}$ & \\
\hline Indiana & $\$ 5.55$ & & & $x$ & $x$ & & $x$ & $x$ & & & & $x$ & & $x$ & & & & $x$ & & $x$ & & $x$ & $x$ \\
\hline lowa & $\$ 3.26$ & & $x$ & $x$ & $x$ & & $x$ & $x$ & $x$ & & & $x$ & $x$ & $\hat{x}$ & & $x$ & $x$ & $x$ & & $\hat{x}$ & $x$ & & \\
\hline Maine & $\$ 11.09$ & $\$ 4.2 \mathrm{M}$ & $x$ & $x$ & & $x$ & $x$ & $x$ & & $x$ & & & & & & $x$ & $\mathrm{x}$ & & & $x$ & $\mathrm{x}$ & & \\
\hline Maryland & $\$ 3.94$ & $\$ 4.5 \mathrm{M}$ & $x$ & $x$ & $x$ & $x$ & $x$ & $x$ & & & & $x$ & & $x$ & & & $x$ & $x$ & & $x$ & & & \\
\hline Massachusetts & $\$ 7.84$ & & & $\hat{x}$ & $\hat{x}$ & & $\hat{x}$ & $\hat{x}$ & $x$ & & & & & $\hat{x}$ & $x$ & $x$ & $\hat{x}$ & & & $\hat{x}$ & & & \\
\hline Minnesota & $\$ 6.16$ & $\$ 6.95 \mathrm{M}$ & $x$ & $\hat{x}$ & & & $x$ & $x$ & & & & & & $\hat{x}$ & & $\hat{x}$ & $\hat{x}$ & & & & $x$ & $x$ & \\
\hline Mississippi & $\$ 7.33$ & & $\hat{x}$ & & & $x$ & $\hat{x}$ & & $x$ & & & & & $\hat{x}$ & & & $\hat{x}$ & & & & & $\hat{x}$ & \\
\hline Montana & $\$ 0.57$ & & & $x$ & & & $x$ & $x$ & & & & & & & & $x$ & $\hat{x}$ & & & $x$ & & & \\
\hline Nebraska & $\$ 4.22$ & & $x$ & $x$ & & $x$ & $x$ & $x$ & $x$ & $x$ & & $x$ & & & & $x$ & $x$ & $x$ & $x$ & $x$ & & & \\
\hline New Hampshire & $\$ 1.28$ & & $\hat{x}$ & $\hat{x}$ & $x$ & & $\hat{x}$ & $\hat{x}$ & $\hat{x}$ & $\hat{x}$ & & $\hat{x}$ & & $x$ & $x$ & $\hat{x}$ & $\hat{x}$ & $x$ & & $\hat{x}$ & & & \\
\hline New Jersey & $\$ 3.73$ & $\$ 6.3 \mathrm{M}$ & $x$ & $x$ & & $x$ & $x$ & & & & & & & $x$ & & & $x$ & & & & $x$ & & \\
\hline New Mexico & $\$ 2.89$ & & & $x$ & $x$ & & $x$ & $x$ & & & & $x$ & & & $x$ & $x$ & $x$ & & $x$ & $x$ & & & \\
\hline New York & $\$ 2.21$ & $\$ 22.2 \mathrm{M}$ & & $x$ & & & $x$ & $x$ & $x$ & & & $\hat{x}$ & & & & $x$ & $\hat{x}$ & & & $\hat{x}$ & & & $x$ \\
\hline North Dakota & $\$ 3.95$ & & & $x$ & $x$ & & & $x$ & & & & & & $x$ & & $x$ & $x$ & $x$ & & & & & \\
\hline Ohio & $\$ 1.94$ & & $x$ & $\hat{x}$ & & $x$ & & $\hat{x}$ & & & $x$ & & & & & $\hat{x}$ & $\hat{x}$ & $\hat{x}$ & & $x$ & $x$ & & \\
\hline Oklahoma & $\$ 0.52$ & & $x$ & & & & $x$ & & $x$ & & & & & $x$ & & & $x$ & & & & & $x$ & \\
\hline Oregon & $\$ 3.47$ & & & $x$ & $x$ & & $\hat{x}$ & $x$ & $\hat{x}$ & & & $x$ & & & & $x$ & $\hat{x}$ & $x$ & & $x$ & & & \\
\hline Pennsylvania & $\$ 3.44$ & & & & $\hat{x}$ & & $x$ & & $\mathrm{x}$ & & & & & & & & $\hat{x}$ & & $x$ & $x$ & & & \\
\hline South Dakota & $\$ 3.65$ & & $x$ & & & $x$ & $x$ & & & $x$ & & & & $x$ & $x$ & & & $x$ & $x$ & & & & \\
\hline Texas & $\$ 0.64$ & & $\hat{x}$ & & & $\hat{x}$ & & & & $\hat{x}$ & & & & & $\hat{x}$ & & $x$ & & $\hat{x}$ & & & & \\
\hline Utah & $\$ 2.91$ & & $x$ & & $x$ & $x$ & $x$ & & $x$ & & & & & $x$ & $x$ & $x$ & $x$ & & & & & $x$ & $x$ \\
\hline Vermont & $\$ 9.38$ & $\$ 1 M$ & $x$ & $x$ & & $x$ & & $x$ & $x$ & $x$ & $x$ & & & & & & $\mathrm{x}$ & & & & & & $x$ \\
\hline Washington & $\$ 3.12$ & $\$ 5.3 \mathrm{M}$ & $\hat{x}$ & $\hat{x}$ & $x$ & & $x$ & $\hat{x}$ & $\hat{x}$ & $\hat{x}$ & & $x$ & & $x$ & & & $\hat{x}$ & & $x$ & $x$ & & & \\
\hline West Virginia & $\$ 3.21$ & & $x$ & & & & $\mathrm{x}$ & & & & & & & $\mathrm{x}$ & $x$ & & & & & & $x$ & & \\
\hline Wisconsin & $\$ 3.00$ & & $\hat{x}$ & $x$ & $x$ & & $\hat{x}$ & $x$ & $x$ & & & $x$ & & $\hat{x}$ & & $x$ & $x$ & $x$ & & $x$ & $\hat{x}$ & & \\
\hline
\end{tabular}


have found that risk taking, high "sensation seeking" youth are more likely to attend to and be convinced by messages with intense, emotionally laden imagery (termed high in "message sensation value") than messages with lower sensation value..$^{58}{ }^{59}$ Sensation seeking, as defined by Zuckerman, ${ }^{60}$ is "the seeking of varied, novel, complex, and intense sensations and experiences, and the willingness to take physical, social, legal, and financial risks for the sake of such experiences" (page 315). High sensation seeking youth are also more likely to smoke ${ }^{61}{ }^{62}$; as a result, intense and emotional countermarketing messages seem to be a promising strategy for youth smoking prevention efforts and have been incorporated in some recent counter-industry campaigns (for example, Legacy and Florida "truth" campaigns).

\section{Counter-industry campaigns and anti-smoking brands} Many of the counter-industry campaigns contain two key elements: combat positive images of smoking in cigarette advertising and expose industry "manipulation". Youth prevention campaigns that include counter-industry messages often include a third element: the development of an anti-smoking "brand". The core of this latter strategy is to market the campaign like other youth brands (for example, Nike, Burton snowboards) while portraying non-smoking as attractive and empowering youth with facts about tobacco and the tobacco industry. The goal is to have youth embrace the brand and with it a tobacco-free lifestyle.

Efforts to directly counter tobacco advertising strive to deglamorise smoking and the images of smokers that the tobacco industry has spent billions of dollars and decades to construct-such as images of rugged, independent men who care little about the long term consequences of smoking (for example, Marlboro man) or the attractive, sexy, and popular people featured in cigarette ads (for example, Virginia Slims "modern woman"). An anti-smoking billboard from California and an ad from Legacy's truth ${ }^{\text {sm }}$ campaign provide vivid examples of anti-smoking campaigns deglamorising and combatting tobacco advertising. The California billboard shows two cowboys similar to the Marlboro man riding horses and one cowboy says to the other, "I miss my lung Bob"-a reference to the fact that one of the original real Marlboro men died of lung cancer. A recent truth ${ }^{\mathrm{sm}}$ commercial shows body bags on horseback in a setting often seen in Marlboro Country ads with a message that says, "What if cigarette ads told the truth". The corresponding truth ${ }^{\mathrm{sm}}$ print has a Surgeon General style warning that says "YEE HAW! You too can be an independent, rugged, macho-looking dead guy".

In addition to combatting tobacco advertising imagery, campaigns have focused on deceptive tobacco industry practices, drawing on industry documents made available from lawsuits with the industry. These documents, combined with public testimony by tobacco company executives, illustrate their attempts to market to youth; manipulate the content of cigarettes with chemicals such as ammonia to increase the addictive impact of cigarettes ${ }^{6364}$; and conceal their knowledge of the health consequences of smoking and the addictive nature of tobacco. Industry documents have provided ample ammunition for countermarketing campaigns wishing to exploit the tobacco industry's manipulation of facts. ${ }^{51}$

Many of the more recent youth prevention campaigns have used counter-industry tactics to help build anti-tobacco youth brands and youth movements against tobacco (for example, Students Working Against Tobacco (SWAT)). These efforts attempt to direct teenagers' desire to assert their own individuality and challenge authority toward combatting smoking and tobacco industry marketing. Biener and Siege ${ }^{65}$ note that tobacco promotional images are attractive to some youth who are "looking for an identity that the images are carefully designed to offer" (page 410). Anti-smoking brands strive to provide an alternative for these youth who are often risk taking and open to the idea of smoking. To capture these youth's attention and to motivate them to resist tobacco industry advertising, countermarketing campaigns feature attractive, "edgy", risk taking teens confronting the tobacco industry with stark facts of the death toll of tobacco and the deadly chemicals in cigarettes. This strategy reflects how campaigns are evolving to more carefully target susceptible audiences with both the types of actors used in the ads and creating ads with stylistic features attractive to high sensation seekers. As noted above, recent research has shown that risk taking, high sensation seeking youth are more likely to smoke and require fast paced and intense ads to capture their attention. Both the Florida and Legacy "truth" campaigns and to a lesser extent, that of Mississippi, have attempted to reach high sensation seeking youth with the use of fast paced, intense ads.

Although the counter-industry approach is compelling and the effectiveness of recent state campaigns validates this strategy, it is not known how, if at all, branding these campaigns enhances their effectiveness. Additional research is needed to compare the relative effectiveness of various youth prevention strategies as well as the concept of branding.

\section{Grassroots efforts to curb tobacco use}

As noted above, some states have developed youth groups working against tobacco use either in conjunction with a mass media campaign or as an independent activity. The primary goal of many of these groups, often referred to as youth empowerment groups, is to create a presence in the community that can change norms about tobacco through peer influence and other supporting activities. These activities include training of group members (media literacy, advocacy, leadership skills, and basic knowledge of tobacco), peer education, public speaking, youth anti-tobacco "summits", distribution of anti-tobacco gear (for example, T shirts, stickers, caps), and policy advocacy. The distribution of gear and sponsorship of events attempt to foster the development of a youth anti-tobacco brand. By distributing attractive, free merchandise and sponsoring popular youth events, the campaign sends a message to teens that their brand is in touch with youth interests and tastes.

Florida's SWAT was the first statewide youth movement against tobacco. In addition, Florida branded its campaign "truth" and distributed "truth" branded gear. Because the Florida programme has experienced large declines in youth smoking ${ }^{34}$ several state prevention programmes have followed Florida's lead by developing groups similar to SWAT. In addition, Legacy funds 17 states through its statewide Youth Movement Against Tobacco Use grant programme. Table 3 lists the states and names of 24 active youth anti-tobacco groups. The table also shows that of the 24 states with activists groups, all but three have a media campaign and 16 of the 21 with campaigns include messages with counter-industry or product focus.

Despite the rapid growth in youth empowerment groups, it is not yet clear how they contribute to changes in youth smoking and/or bring about change in the tobacco control environment. Would smoking rates have changed as rapidly in Florida in the absence of SWAT? Was the investment in developing SWAT cost effective relative to the mass media campaign? Legacy's Youth Empowerment grants are currently being evaluated, as are a number of state programmes through CDC Prevention Research Centers or state programme evaluations. Evaluations of youth empowerment programmes must attend not only to the direct effects of participation in these groups on smoking behaviour but also to the diffusion of grassroots efforts throughout the community through media coverage of sponsored events and/or discussion among peers that extends beyond those who participated. 
Table 3 Youth activist groups

\begin{tabular}{|c|c|c|c|}
\hline State & Activist group & $\begin{array}{l}\text { Media } \\
\text { campaign }\end{array}$ & $\begin{array}{l}\text { Industry/ } \\
\text { chemical theme }\end{array}$ \\
\hline California & CYAN (California Youth Advocacy Network) & $\mathrm{x}$ & $x$ \\
\hline Colorado & Get R!EAL (Resist! Expose Advertising Lies) & $x$ & $x$ \\
\hline Delaware & KBG (Kick Butts Generation) & $x$ & $x$ \\
\hline Florida & SWAT (Students Working Against Tobacco) & $x$ & $x$ \\
\hline Georgia & Youth in CHARGe! (Coalition for a Healthy and Responsible Georgia) & $X$ & \\
\hline Hawaii & REAL & $x$ & \\
\hline lowa & JEL (Just Eliminate Lies) & $x$ & $x$ \\
\hline Kansas & TASK (Teens Against Smoking in Kansas) & $x$ & \\
\hline Kentucky & START (Students Teaching Awareness Regarding Tobacco) & & \\
\hline Massachusetts & Get Outraged & $x$ & $x$ \\
\hline Minnesota & Target Market & $x$ & $X$ \\
\hline Mississippi & Question It & $x$ & $x$ \\
\hline New Hampshire & YNOT NH (Youth Network Opposing Tobacco in NH) & $x$ & $x$ \\
\hline New Jersey & REBEL (Reaching Everyone By Exposing Lies) & $x$ & $x$ \\
\hline New York & Reality Check & $x$ & \\
\hline Oklahoma & SWAT/Reality & $x$ & $x$ \\
\hline Rhode Island & WORD & $x$ & $x$ \\
\hline South Carolina & Statewide Youth Movement Against Tobacco & & \\
\hline South Dakota & Get RAGE (Get Real. Get Active. Get Going. Get Empowered) & $x$ & $x$ \\
\hline Utah & Phoenix Alliance & $x$ & $x$ \\
\hline Vermont & OVX (Our Voices Xposed), ages 13-17 VKAT (VT Kids Against Tobacco) & $x$ & \\
\hline Washington & SOUL (Saving Ourselves from Unfiltered Lies) & $x$ & $X$ \\
\hline West Virginia & $\mathrm{T}^{3}$ (Teens Terminating Tobacco) & & \\
\hline Wisconsin & FACT (Fighting Against Corporate Tobacco) & $x$ & $x$ \\
\hline
\end{tabular}

\section{EFFECTIVE COUNTERMARKETING CAMPAIGN STRATEGIES: WHAT WE KNOW}

Our characterisation of state and national campaigns illustrates the diversity of thematic and strategic approaches to mass media campaigns. While counter-industry and branding approaches are fashionable, based on the experimental literature and results from recent campaigns, it is not clear if any particular message strategy has greater empirical support than others. Does content matter or is it simply a question of achieving substantial exposure? For guidance on effective message strategies, one can look to laboratory experiments and qualitative studies that attempt to assess audiences' receptivity to messages and/or by assessing which strategies have produced declines in smoking in experimental or real world settings. Unfortunately, for the latter, the lack of an impact may be due to the dose of advertising exposure, the message strategy, other complementary interventions, or some combination of all of these factors. Although focus groups and laboratory experiments provide compelling and intuitive findings, it is not clear how the audiences' short term receptivity to message strategies translates to changes in smoking behaviour. As potential evidence in support of this notion, the current laboratory and qualitative literature does not provide a strong consensus as to which strategies are most effective or well received.

\section{Laboratory and qualitative studies assessments of anti-smoking messages}

A number of qualitative studies, relying on focus groups and expert opinions, have attempted to provide guidance on which message themes are most effective. Based on transcripts from a number of focus group studies, Goldman and Glantz ${ }^{51}$ determined that industry manipulation and secondhand smoke themes were the most effective strategies among both teens and adults. Another focus group study of youth funded by the CDC found that ads that "graphically, dramatically, and emotionally portray the serious consequences of smoking" were the most effective. The study concluded that the power of these ads was due to their reliance on real world stories of smokers, such as Pam Laffin. ${ }^{39}$ This study found that the industry manipulation ads only resonated with youth in California where such an approach was familiar to teens. Finally, ads that used a "choice" theme, such as Philip Morris's "TDS" campaign, were consistently ranked lowest by teens.

Copy testing procedures conducted by McKenna and Williams, ${ }^{66}$ where teens viewed a series of television and print ads and responded to closed ended items gauging their response to the ads, revealed that the counter-industry approach was deemed ineffective by a sample of youth. Similarly, Reister and Linton ${ }^{67}$ advocated messages that focus on short term health and cosmetic consequences and discredited the industry manipulation theme based on focus group discussions. McKenna et a $l^{68}$ consulted commercial marketing experts and concluded that messages focusing on social perceptions of smoking norms (the number of teens who smoke) were the favoured strategy. No clear patterns emerge across studies. The conflicting findings may be due to inherent limitations of such qualitative approaches and/or differences in the specific ads chosen to represent the various message themes. For example, $\mathrm{Job}^{69}$ reports that fear based approaches usually test well in focus groups but almost never work to change behaviour. It is also unclear whether the opinions of commercial marketing experts translate into successful practice. In sum, the evidence from focus groups and expert opinions regarding the most effective message strategies is conflicting and indeterminate.

Laboratory experiments offer the methodological advantages of increased controls and provide "forced exposure" to specific countermarketing messages, whereby researchers ensure that a respondent views a particular advertisement or series of ads. Investigators at the University of CaliforniaIrvine have conducted a series of laboratory experiments aimed at identifying the causal effects of countermarketing messages and comparing thematic approaches. Pechmann and Ratneshwar ${ }^{70}$ found that print ads that focused on deglamorising the social imagery (attractiveness and "coolness") of smoking produced less favourable judgments of the common sense and personal appeal of smokers among California seventh graders. However, a more recent study ${ }^{50}$ concluded that messages focusing on smokers' endangering their family, discussing smokers' negative life circumstances (depicting smokers as unattractive and insecure), and modelling refusal skills were most effective in producing negative intentions to smoke cigarettes among youth who had 
previously experimented with cigarettes. Messages concerned with the health (disease and death) and cosmetic (bad breath and yellow teeth) consequences of smoking and the manipulative marketing strategies of the tobacco industry were ineffective in reducing intentions to smoke.

Although laboratory approaches offer the aforementioned methodological advantages, it is unclear whether findings from the laboratory translate into real world settings. In addition, laboratory experiments provide only a brief exposure to countermarketing messages and assess immediate outcomes (perceived effectiveness, intentions to smoke), not subsequent behaviour. This knowledge gap can explain some of the variation observed in results from message theme studies. It is unclear whether evaluations of perceived influence are predictive of subsequent changes in behaviour. Furthermore, more exposures are necessary to drive home complex messages, according to Tellis. ${ }^{71}$ This indicates that short term measures of ad response might not capture the cumulative effects of a more complex message. More research is needed to tie self reported measures of "perceived effectiveness" and subjective ad evaluations by researchers to changes in outcomes.

The qualitative and experimental literature also does not appear to distinguish between young teens and "tweens" (10-12 year olds) and older teens. School based prevention education research has shown that young children respond to short term health effects of smoking (for example, shortness of breath, inability to keep up in sports) and the cosmetic consequences (for example, wrinkles, bad breath, stained teeth). Very few campaigns currently take this approach. Notable exceptions are the Arizona and Texas campaigns. Arizona's youth prevention campaign's tagline, "Tobacco, the tumourcausing, teeth staining, smelly, puking habit", and the Texas pilot study that used the tagline, "tobacco is foul" have focused on tobacco as a disgusting habit. Are these campaigns primarily effective with younger but not older teens? Are counter-industry approaches too complex for younger teens to understand? This approach requires some understanding of the notion of an industry, marketing practices, and the manipulation of the content of cigarettes. Should campaigns develop different strategies for both of these audiences? Alternatively, is it sufficient to take a long term strategy to youth prevention by reducing tobacco use among adults, which in turn, influences youth tobacco use? The experiences of experimental studies and evaluations of state and national campaigns are currently too limited to provide strong guidance on effective message strategies for youth prevention.

\section{DISCUSSION}

The current experimental research indicates that mass media prevention campaigns are effective and suggests that they may be most effective when complemented with school or community based programmes. This research, in combination with the experiences from California, Florida, and Massachusetts and recommendations from CDC, has led states to adopt comprehensive tobacco control programmes that consist of a wide array of interventions. However, this conclusion is based on relatively few studies. The success of the national truth ${ }^{\mathrm{sm}}$ campaign, ${ }^{14}{ }^{42}$ Florida campaign before complementary programmes, ${ }^{15}$ and the impact of an antidrug media campaign in Kentucky ${ }^{47}$ suggest that an aggressive, targeted, and/or well funded media campaign alone may be sufficient to affect youth smoking. Mass media campaigns have the advantage of reaching a large fraction of target audiences relatively inexpensively compared with community based programmes. However, interpersonal contacts made by the latter may affect greater change. Additionally, complex changes in social norms and behaviour may require a wealth of messages from varied and diverse sources, including interpersonal communication (as often delivered by community based programmes) and countermarketing messages in the media. ${ }^{43}$ Additional studies that vary the level of campaign exposure and concomitant interventions would help elucidate the most cost effective mix of programmes to curb smoking.

Summarising the findings from laboratory and qualitative studies of message strategies (that is, message content and emotional appeal) as well as experimental and quasiexperimental evaluations of media campaigns indicates that no message pattern can guarantee consistent effectiveness. It appears that programme success may be largely dependent on other variables, including level of exposure, degree of focus on a target audience, and the presence of complementary school and/or community programmes. Pechmann ${ }^{72}$ recently argued that at least four issues must be addressed in the systematic design of anti-tobacco campaigns: (1) thematic content, (2) executional style, (3) target audience, and (4) budget (sufficient to produce considerable exposure). While limited research has addressed thematic content (for example, Pechmann et $a l^{50}$ ), target audience, ${ }^{35}$, and levels of exposure (for example, Hornik ${ }^{43}$ ), even fewer studies have explicitly focused on the executional style of anti-smoking advertisements. A number of studies evaluating the effectiveness of antidrug public service announcements have examined the impact of production or design features on differences in ad recall, evaluation, and impact, particularly with regard to high sensation seekers. ${ }^{475873}$ Work on this subject needs to be extended to the area of tobacco countermarketing research, which would better inform campaign designers of how messages should be developed to maximise attention and effect.

In addition, very few experimental studies examine the effects of message theme, emotional content, and production features simultaneously. With the notable exceptions of Pechmann and Reibling ${ }^{74}$ Pechmann et al, ${ }^{50}$ and Goldman and Glantz, ${ }^{51}$ research projects have isolated their examinations to only one class of content. Studies that examine message themes have examined only message themes, while work in the antidrug paradigm has focused more on executional style and emotional appeal. Researchers should examine the effects of message theme, emotional content, and production features simultaneously and then connect each of these features to outcomes. A synthesis of these fragmented research paradigms would illuminate potential interactions and isolate the most significant predictors of message success. Clearly, there is much to learn about the specific characteristics of tobacco countermarketing advertisements that contribute to an audience's response, cognition, and ultimate persuasion: researchers must undertake complex and multifaceted research projects to create better advertisements and, ultimately, more successful campaigns.

The lack of consensus in the literature on the relative effectiveness of various message strategies may be due to the failure to adequately control for the production quality of the specific advertisements being studied and the extent to which these messages have been tailored to the populations most at risk. Research suggests that the selection of appropriate message themes can be achieved through extensive and theory driven formative research, followed by carefully crafting and targeting messages to populations most at risk, including high sensation seekers, those open to smoking in the future, or specific age, sex, or racial/ethnic groups. ${ }^{14} 4047527576$ Rather than attempting to draw broad conclusions about the efficacy of particular thematic strategies over time, researchers would be better served to pay careful attention to the existing beliefs and attitudes of the target audience to inform message design. Cappella et $a l^{75}$ and Hornik and Woolf ${ }^{77}$ describe strategies for campaign development based on theory and beliefs held by the target audience. In short, campaign planners identify existing beliefs and attitudes among the target audience and develop campaign messages to address the beliefs and attitudes that (1) are reasonably addressed with media messages, (2) have room for "improvement," and (3) demonstrate a strong association with smoking behaviour. This 
approach assumes that appropriate message strategies change over time and vary across target audiences and can explain the inconsistent findings across studies and over time regarding effective message themes.

One promising yet relatively unexploited research tool that could aid in message design is the use of Knowledge Networks WebTV capability to test advertisements and conduct surveys with nationally representative samples of youth and adults. Panels of households have been recruited to participate in surveys and experiments in exchange for free access to WebTV. This system can be used to expose subjects to a variety of styles of ads over time to examine both the appeal of ads and their impact on salient beliefs and attitudes.

\section{Future directions in media and countermarketing}

Tobacco control advocates have used mass media campaigns as a vehicle to combat teen and adult smoking for over 35 years. Surprisingly, however, there is only limited evidence that countermarketing is a cost effective strategy in isolation and the current literature provides little guidance toward designing successful campaigns. In addition, subtler questions about the effects of message theme, emotional content, and stylistic features remain unanswered. Given these uncertainties and the multitude of campaign approaches currently being employed by state and national campaigns, where does the future of countermarketing lead?

Recent state budget crises have caused state legislatures to dramatically cut funding for tobacco control programmes in order to fill budget deficits. ${ }^{1}$ As a result, research must identify proven, cost effective tobacco control strategies to secure funding for the future. From a public health perspective, the goal of reducing tobacco related morbidity and mortality remains paramount. As youth targeted media campaigns mature, research needs to establish their long term public health impact by answering two key questions: (1) Can youth focused media campaigns produce long term behavioural changes or simply delay the onset of cigarette smoking to early adulthood? (2) What synergies exist between media campaigns and other tobacco control interventions (for example, school based prevention, excise taxes, clean indoor air laws, community based programmes)? Timely research needs to address these issues to provide empirical support for countermarketing campaigns as a component of comprehensive tobacco control programmes.

Diverse strategies currently employed in states provide the unique opportunity to compare and contrast campaign approaches in the context of comprehensive tobacco control programmes. It is clear that the industry manipulation strategy is a popular thematic choice among youth targeted countermarketing campaigns. However, the context of concurrent school, community, and policy initiatives complicates efforts to capitalise on national variation in approaches. Is it possible to adequately control for other programme activities and contextual factors? Will the industry manipulation strategy "wear out" once teens accept the notion that the tobacco industry targets them and uses manipulative strategies? If so, where do state and national efforts go from there?

State and national campaigns overlap substantially in target audience and, in some cases, thematic approach. Little is understood about potential interactions between state and national campaigns. How do state anti-tobacco campaigns complement national countermarketing efforts? Should state campaigns employ dissimilar messages to complement national efforts, or do teens benefit from extensive exposure to analogous messages? Are there ways to combine resources to maximise the impact of mass media countermarketing campaigns?

Recent evidence suggests that the tobacco industry has shifted its focus to target 18-24 year olds with aggressive marketing and promotions, particularly in "adult only" establishments such as bars and clubs. ${ }^{78}$ Perhaps not by coincidence, Lantz ${ }^{80}$ reveals that the rate at which young adults who have experimented with cigarettes become regular smokers has increased in recent years. Thus, young adults may emerge as the key audience for future countermarketing efforts. Do tobacco countermarketing messages aimed at teens also reach and resonate among young adults ( $18-24$ years)? How can messages be tailored and targeted to young adults to combat recent upward trends in smoking behaviour?

Finally, the home media environment has become increasingly complex in recent years. Reaching teens through television is increasingly difficult, as technology such as Tivo allows viewers to avoid viewing commercials, and other media (video games, internet) compete for their attention. How will broadcast media campaigns continue to reach teens? What are the alternative outlets, and how effective are they? To date, state and national campaigns, with the exception of TDS, have avoided reaching teens through schools via Channel One-an in-school television network. Is this a viable option for youth prevention, or is this approach counter to the commonly used industry manipulation messages that challenge authority because it is in the context of schools and authority figures?

\section{Authors' affiliations}

M C Farrelly, J Niederdeppe, J Yarsevich, Research Triangle Institute, Research Triangle Park, North Carolina, USA

\section{REFERENCES}

1 Campaign for Tobacco-Free Kids. Show us the money: an update on the states' allocation of tobacco settlement dollars, 2002. URL: http://www.tobaccofreekids.org/ reports/settlemtns/2002

2 Farrelly MC, Pechacek TF, Chaloupka FJ. The impact of tobacco control program expenditures on aggregate cigarette sales: 1981-1998. Cambridge, Massachusetts: National Bureau of Economic Research Working Paper 8691, 2001.

3 Federal Trade Commission. Report to Congress for 2000 pursuant to the federal cigarette labeling and advertising act. Washington DC: Federal Trade Commission, 2002.

4 Cruz T, Weiner M, Schuster D, et al. Growth of tobacco-sponsored bars and clubs from 1996-2000. Paper presented at the Annual Meeting of the American Public Health Association, Boston, Massachusetts, 12-16 November 2000.

5 Sepe E, Glantz SA. Bar and club tobacco promotions in the alternative press: targeting young adults. Am J Public Health 2002;92:75-8.

6 Simonich WL. Government antismoking policies. New York: Peter Lang Publisher, 1991

7 Hamilton JL. The demand for cigarettes: advertising, health scare, and the cigarette advertising ban. Review of Economics and Statistics 1972;54:401-11

8 Warner KE. The effects of the antismoking campaign on cigarette consumption. Am J Public Health 1977:67:645-50.

9 Warner KE. Clearing the airwaves: the cigarette ad ban revisited. Policy Analysis 5:435-50, 1979. Reprinted in: Anderson J, ed. Cases in public policy-making, 2nd ed. New York: Holt, Rinehart and Winston, 1982:244-56.

10 Lewit EM, Coate D, Grossman M. The effects of government regulation on teenage smoking. Journal of Law and Economics 1981;24:545-69.

11 Schneider L, Klein B, Murphy KM. Governmental regulation of cigarette health information. Journal of Law and Economics 1981;24:575-612.

12 O'Keefe MT. The anti-smoking commercials: a study of television's impact on behavior. Public Opinion Quarterly 1971;35:242-8.

13 US Department of Health and Human Services. Reducing the health consequences of smoking: 25 years of progress. A report of the Surgeon General, 1989. Rockville, Maryland: Public Health Service, Centers for Disease Control, Office on Smoking and Health, 1989. (DHHS Publication No (CDC) 89-8411.)

14 Farrelly MC, Healton CH, Davis KC, et al. Getting to the truth: evaluating national tobacco countermarketing campaigns. Am J Public Health 2002;92:901-7.

15 Sly DF, Heald GR, Ray S. The Florida 'truth' antitobacco media evaluation: design, first-year results, and implications for planning future state media evaluations. Tobacco Control 2001;10:9-15.

16 Bauman KE, LaPrelle J, Brown JD, et al. The influence of three mass media campaigns on variables related to adolescent cigarette smoking: results of a field experiment. Am J Public Health 1991;81:597-604.

17 Flynn BS, Worden JK, Secker-Walker RH, et al. Prevention of cigarette smoking through mass media intervention and school programs. Am J Public Health 1992;82:827-34.

18 Perry CL, Kelder SH, Murray DM, et al. Communitywide smoking prevention: long-term outcomes of the Minnesota heart health program and the class of 1989 study. Am J Public Health 1992;82:1210-15. 
19 University of Texas-Houston. Texas tobacco prevention initiative media campaign and community program: effects among children and adults. University of Texas-Houston, Texas: Health Science Center, 2001.

20 Flay BR. Mass media and smoking cessation: a critical review. Am J Public Health 1987;77:153-60.

21 Flynn BS, Worden JK, Secker-Walker RH, et al. Mass media and schoo interventions for cigarette smoking prevention: effects two years after completion. Am J Public Health 1994;84: 1 148-50.

22 Halfstad A, Aaro LE, Engeland A, et al. Provocative appeals in anti-smoking mass media campaigns targeting adolescents - the accumulated effect of multiple exposures. Health Education Research 1997; 12:227-36.

23 Shannon K. State launches antismoking quack attack. 25 September 2000. URL: www.tobaccoweek.com

24 Biener L, Harris JE, Hamilton W. Impact of the Massachusetts tobacco control program: population based trend analysis. BM 2000;321:351-4.

25 Hu TW, Sung HY, Keeler TE. Reducing cigarette consumption in California: tobacco taxes vs. an antismoking media campaign. Am J Public Health 1995;85:1218-22.

26 Pierce JP, Gilpin EA, Emery SL, et al. Has the California tobacco control program reduced smoking? JAMA 1998;280:893-9.

27 Murray DM, Prokhorov AV, Harty KC. Effects of a statewide antismoking campaign on mass media messages and smoking beliefs. Prev Med 1994;23:54-60.

28 Popham WJ, Potter LD, Hetrick MA, et al. Effectiveness of the California 1990-1991 tobacco education media campaign. Am J Prev Med $1994 ; 10: 319-26$

29 Johnston LD, O'Malley PM, Bachman JG. Monitoring the Future national survey results on drug use, 1975-2001. Volume I: Secondary school students. Bethesda, Maryland: National Institute on Drug Abuse, 2002

30 Commonwealth of Massachusetts. Preventing tobacco use among Massachusetts youth: programs and results. Commonwealth of Massachusetts Department of Education, January 2002.

31 Siegel $M$, Biener $L$. The impact of an antismoking media campaign on progression to established smoking: results of a longitudinal youth study. Am J Public Health 2000:90:380-6.

32 Morbidity and Mortality Weekly Report. Decline in cigarette consumption following implementation of a comprehensive tobacco prevention and education program-Oregon, 1996-1998. 48:140-3. Washington DC: CDC, US Government Printing Office, 26 February 1999.

33 Centers for Disease Control. Effectiveness of school-based programs as a component of a statewide tobacco control initiative-Oregon, 1999-2000. MMWR Morb Mortal Wkly Rep 2001;50:663-6.

34 Bauer UE, Johnson TM, Hopkins RS, et al. Changes in youth cigarette use and intentions following implementation of a tobacco control program: findings from the Florida Youth Tobacco Survey, 1998-2000. JAMA 2000;284:723-8.

35 Sly DF, Hopkins RS, Trapido E, et al. Influence of a counteradvertising media campaign on initiation of smoking: the Florida "truth" campaign. Am J Public Health 2001;91:233-8.

36 Wyllie A, Zhang J, Casswell S. Responses to televised alcohol advertisements associated with drinking behavior of 10-17 year olds. Addiction 1998;93:361-71

37 McMillen RC, Keller S, Thoms T, et al. The 1998 Mississippi youth tobacco survey, Volume 1, Issue 1. Prepared for the Mississippi Department of Health, 1999.

38 Centers for Disease Control. Youth tobacco surveillance-United States, 2000. MMWR Morb Mortal Wkly Rep 2001;50(SS-4): 1-84.

39 Teenage Research Unlimited. Youth focus groups to assess tobacco-use-prevention ads. North Brook, Illinois: Teenage Research Unlimited, 1999.

40 Farrelly MC, Davis KC, Yarsevich JM, et al. Getting to the truth: assessing youths' reactions to the truth and 'Think. Don't Smoke' tobacco countermarketing campaigns. Legacy First Look Report 9. Washington DC, 2002

41 Novelli WD. Don't smoke, buy Marlboro. BMU 1999;318:1296.

42 Farrelly MC. Future directions in youth tobacco countermarketing campaigns. Presented at the 2002 National Conference on Tobacco or Health, San Francisco, California, 19-21 November 2002

43 Hornik RC. Public health communication: evidence for behavior change. Mahwah, New Jersey: Lawrence Erlbaum, 2002.

44 Roccella EJ. The contributions of public health education toward the reduction of cardiovascular disease mortality: experiences from the national high blood pressure education program. In: Hornik RC, ed. Public health communication: evidence for behavior change. Mahwah, New Jersey: Lawrence Erlbaum, 2002.

45 Williams AF, Wells JK, Reinfurt DW. Increasing seat belt use in North Carolina. In: Hornik RC, ed. Public health communication: evidence for behavior change. Mahwah, New Jersey: Lawrence Erlbaum, 2002.

46 Hill D, White V, Marks R, et al. Changes in sun-related attitudes and behaviors, and reduced sunburn prevalence in a population at high risk of melanoma. In: Hornik RC, ed. Public health communication: evidence for behavior change. Mahwah, New Jersey: Lawrence Erlbaum, 2002.

47 Palmgreen P, Donohew L, Lorch EP, et al. Television campaigns and sensation seeking targeting of adolescent marijuana use: a controlled time series approach. In: Hornik RC, ed. Public health communication: evidence for behavior change. Mahwah, New Jersey: Lawrence Erlbaum, 2002

48 Centers for Disease Control and Prevention. Best practices for comprehensive tobacco control programs. Atlanta, Georgia: US
Department of Health and Human Services: Centers for Disease Control and Prevention, National Center for Chronic Disease Prevention and Health Promotion, Office on Smoking and Health, August 1999

49 Siegel M. Antismoking advertising: figuring out what works. Journal of Health Communication 2002;7: 157-62.

50 Pechmann C, Goldberg ME, Reibling ET, et al. Using protection motivation theory to identify effective antismoking ads. Irvine, California: California Tobacco-Related Disease Research Program, 2001.

51 Goldman LK, Glantz SA. Evaluation of antismoking advertising campaigns. JAMA 1998;279:772-7.

52 Worden JK, Flynn BS, Solomon L, et al. Using mass media to prevent cigarette smoking among adolescent girls. Health Education Quarterly 1996;23:453-68.

53 Flynn BS, Worden JK, Secker-Walker RH, et al. Long-term responses of higher and lower risk youths to smoking prevention interventions. Prev Med 1997; 26:389-94.

54 Nabi R. A cognitive-functional model for the effects of discrete negative emotions on information processing, attitude change, and recall. Communication Theory 1999;9:292-320.

55 Biener L. Adult and youth response to the Massachusetts antitobacco television campaign. Journal of Public Health Management Practice 2000;6:40-4.

56 Montazeri A, McEwen J. Effective communication: perception of two antismoking advertisements. Patient Education and Counseling 1997;30:29-35.

57 Miller C, Burgoon M, Alvaro E, et al. An assessment of the Arizona antitobacco use media campaign. Paper presented at the annual conference of the American Public Health Association: Boston, Massachusetts, November 2000

58 Donohew L, Lorch EP, Palmgreen P. Sensation seeking and targeting of televised anti-drug PSAs. In: Donohew L, Bujoski WJ, Sypher H, eds. Persuasive communication and drug abuse prevention. Hillsdale, New Jersey: Lawrence Erlbaum, 1991.

59 Palmgreen P, Donohew L, Lorch EP, et al. Television campaigns and adolescent marijuana use: tests of sensation seeking targeting. Am J Public Health 2001;91:292-6.

60 Zuckerman M. The psychophysiology of sensation seeking. Journal of Personality 1990;58:314-45.

61 Donohew L, Helm D, Lawrence P, et al. Sensation seeking, marijuana use and responses to prevention messages: implications for public health campaigns. In: Watson R, ed. Prevention and treatment of drug and alcohol abuse. Clifton, New Jersey: Humana Press, 1990:73-93.

62 Kopstein AN, Crum RM, Celentano DD, et al. Sensation seeking needs among 8 th and 11 th graders: characteristics associated with cigarette and marijuana use. Drug Alcohol Depend 2001;62:195-203.

63 Kessler DA. The control and manipulation of nicotine in cigarettes. Tobacco Control 1994;3:362-9.

64 Brown and Williamson. Root technology: handbook for leaf blenders and product developers. Legacy Tobacco Documents Library. 22 August 1995. URL: http://legacy.library.ucsf.edu/

65 Biener L, Siegel M. Tobacco marketing and adolescent smoking: more support for a causal inference. Am J Public Health 2000;90:407-11.

66 McKenna JW, Williams KN. Crafting effective tobacco counter-advertisements: lessons from a failed campaign directed at teenagers. Public Health Rep 1993;108(suppl 1):85-9.

67 Reister T, Linton M. Designing an effective counteradvertising campaign: Arizona. Cancer 1998;83:2746-51.

68 McKenna J, Gutierrez K, McCall K. Strategies for an effective youth countermarketing program: recommendations from commercial marketing experts. Journal of Public Health Management Practice 2000;6:7-13.

69 Job R. Effective and ineffective use of fear in health promotion campaigns. Am J Public Health 1988;78: 163-7.

70 Pechmann C, Ratneshwar S. The effects of antismoking and cigarette advertising on young adolescents' perceptions of peers who smoke. Journal of Consumer Research 1994;21:236-51.

71 Tellis GJ. Effective frequency: one exposure or three factors. Journal of Marketing Research 1997;75-80.

72 Pechmann C. Changing adolescent smoking prevalence: impact of advertising interventions. Changing adolescent smoking prevalence. Smoking and Tobacco Control Monograph No. 14. Bethesda, Maryland: US Department of Health and Human Services, National Institutes of Health, National Cancer Institute, November 2001, 2002.

73 Lorch EP, Palmgreen P, Donohew L, et al. Program context, sensation seeking, and attention to televised anti-drug public service announcements. Human Communication Research 1994;7:390-412.

74 Pechmann C, Reibling ET. Antismoking advertising campaigns targeting youth: case studies from USA and Canada. Tobacco Control 2000;9(suppl II):ii 18-31.

75 Cappella JN, Fishbein $M$, Hornik R, et al. Using theory to select messages in antidrug campaigns. In: Rice RE, Atkin CK, eds. Public communication campaigns. Thousand Oaks, California: Sage, 2001

76 Earle R. The art of cause marketing: how to use advertising to change personal behavior and public policy. Chicago, Illinois: NTC Business Books, 2000

77 Hornik R, Woolf KD. Using cross-sectional surveys to plan message strategies. Social Marketing Quarterly 1999:5:34-41

78 Ling PM, Glantz SA. Why and how the tobacco industry sells cigarettes to young adults: evidence from industry documents. Am J Public Health 2002;92:908-16.

79 Sepe E, Ling PM, Glantz SA. Smooth moves: bar and nightclub tobacco promotions that target young adults. Am J Public Health 2002:92:414-9.

80 Lantz PM. Smoking on the rise among young adults: implications for research and policy. Tobacco Control 2003;12(suppl I):60-70. 